\title{
Lesión aislada de la sindesmosis tibioperonea inferior
}

\author{
Isolated injury of the lower tibioperoneal syndesmosis \\ Luis Gerardo Domínguez Gasca, * Carlos Iván Andrade Aguilar,* \\ Edgar Turrubiates Lucero, ${ }^{*}$ Luis Gerardo Domínguez Carrillo ${ }^{\ddagger}$ \\ Citar como: Domínguez GLG, Andrade ACl, Turrubiates LE, Domínguez CLG. Lesión aislada de la sindesmosis \\ tibioperonea inferior. Acta Med GA. 2022; 20 (1): 99-100. https://dx.doi.org/10.35366/103567
}

Masculino de 25 años que tres semanas atrás sufrió inversión del tobillo derecho durante la marcha, se automanejó con férula AeroCast por dos semanas, permaneciendo asintomático por tres días en que inició trote de $5 \mathrm{~km}$, presentando al final dolor intenso y edema de cara anterior de tobillo. A la exploración dirigida: edema de la zona, dolor intenso durante pruebas de Hopkinson y de estrés en rotación externa del pie, por lo que con diagnóstico de lesión de la sindesmosis tibioperonea inferior se solicitan radiografías (Figura 1A y B) y resonancia magnética (Figura 2), confirmando diagnóstico. Se efectuó fijación de la sindesmosis con el sistema TightRope, que ancla los extremos de la tibia y el peroné mediante un cordón de polietileno trenzado (Figura 1C) y reconstrucción de la cápsula articular. Se colocó inmovilizador de tobillo y se canalizó a las tres semanas a rehabilitación.

Las lesiones de la articulación tibioperonea distal representan aproximadamente $1 \%$ de las lesiones ligamentosas del tobillo, si bien infrecuentes, se asocian a $20 \%$ de las lesiones de esguince de tobillo, se les observa con mayor frecuencia en personas de ambos géneros entre 18 y 34 años de edad. Su diagnóstico requiere un alto índice de sospecha, ya que la lesión puede pasar inadvertida y se confunde frecuentemente con el esguince lateral del tobillo, ocasionando dolor crónico de esta articulación. Su mecanismo de producción es la rotación externa del pie en relación con la tibia. ${ }^{1}$ Las

Figura 1:

A) Radiografía lateral de tobillo que muestra edema en cara anterior (flecha negra), como hallazgo os trigonum fijo al astrágalo (flecha blanca). B) Radiografía anteroposterior de tobillo que muestra: diástasis de la sindesmosis tibioperonea inferior, con ausencia de sobreposición peroneotibial (flecha blanca). C) Radiografía anteroposterior de tobillo que muestra resolución mediante el sistema TightRope, que ancla los extremos de la tibia y el peroné mediante un cordón de polietileno trenzado.
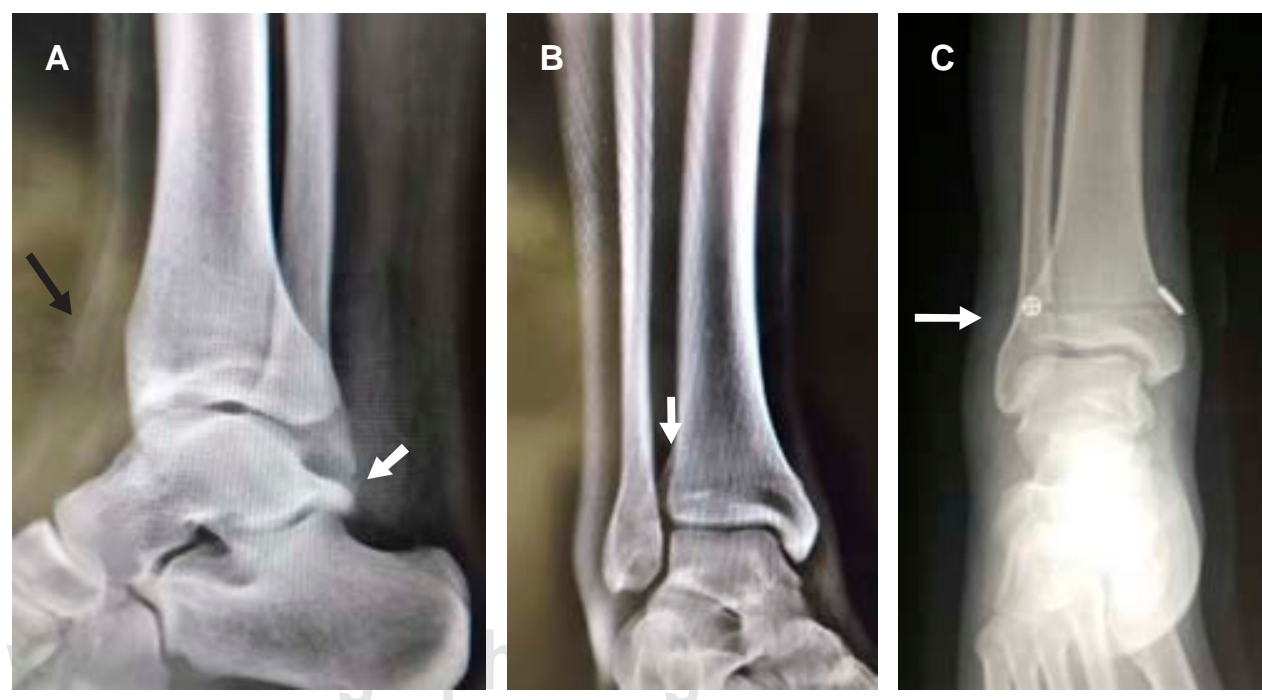

\footnotetext{
* Ortopedista, Cirugía Articular. División de Cirugía del Hospital Angeles León. León, Guanajuato, México.

* Especialista en Rehabilitación. Catedrático de la Facultad de Medicina de León, Universidad de Guanajuato. México.
}

Correspondencia:

Dr. Luis Gerardo Domínguez Gasca

Correo electrónico: luisdom88@hotmail.com

www.medigraphic.com/actamedica 

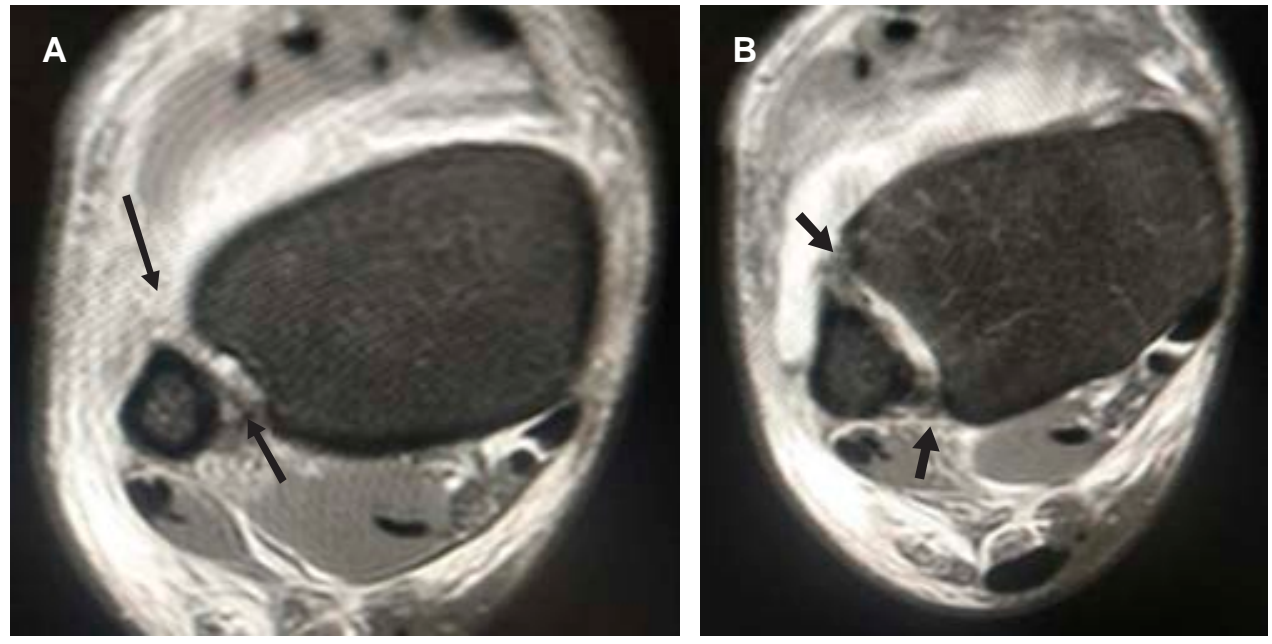

Figura 2:

Imágenes de resonancia magnética en cortes axiales de tobillo, ponderadas en T2 que muestran ruptura de los ligamentos tibioperoneos anterior, posterior e interóseo (flechas negras) y líquido intraarticular con diástasis de la sindesmosis.

lesiones pueden ser aisladas ${ }^{2} \mathrm{o}$ asociadas a fracturas del tobillo causadas por rotación externa y pronación (Weber tipo C), supinación y rotación externa (Weber tipo B) y fracturas proximales del peroné (Maisonneuve). Las pruebas son: 1) de Hopkinson (compresión del peroné y la tibia en un punto por encima de la parte media de la pierna produce la separación del peroné y la tibia en su unión distal causando dolor); 2) prueba de estrés rotación externa: consiste en estabilizar la pierna con la rodilla en $90^{\circ}$ y realizar rotación externa del pie, lo cual causa dolor a nivel de la sindesmosis tibioperonea, si es positiva. Habitualmente las radiografías simples son suficientes para el diagnóstico, ante la duda, la resonancia magnética nuclear y la artroscopia del tobillo tienen un alto porcentaje de diagnóstico. ${ }^{3}$ Clínica y radiológicamente la lesión se clasifica en tres grados: el grado 1: sindesmosis estable con dolor local moderado y hallazgos radiográficos normales. Suelen mejorar con tratamiento conservador; el grado 2: lesión sindesmótica parcial con hallazgos radiográficos normales, pero pruebas de rotación externa y estrés test positivos, la literatura difiere entre tratamiento conservador o quirúrgico; y el grado 3: ruptura completa de los ligamentos de la sindesmosis, con hallazgos radiográficos patológicos (diástasis visible de la articulación), que requiere cirugía, ${ }^{4}$ la cual puede ser abierta con colocación de uno o dos tornillos (forma clásica), por reconstrucción mediante artroscopia o con métodos más modernos utilizando el sistema TightRope que ancla los extremos de la tibia y el peroné mediante un cordón de polietileno trenzado (utilizado en el caso que se presenta).

\section{REFERENCIAS}

1. Vopat ML, Vopat BG, Lubberts B, DiGiovanni CW. Current trends in the diagnosis and management of syndesmotic injury. Curr Rev Musculoskelet Med. 2017; 10 (1): 94-103. doi: 10.1007/s12178017-9389-4.

2. Grobterlinden LG, Hartel M, Yamamura J, Schoennagel B, Bürger N, Krause $M$ et al. Isolated syndesmotic injuries in acute ankle sprains: diagnostic significance of clinical examination and MRI. Knee Surg Sports Traumatol Arthrosc. 2016; 24 (4): 1180-1186. doi: 10.1007/ s00167-015-3604-x.

3. Switaj PJ, Mendoza M, Kadakia AR. Acute and chronic injuries to the syndesmosis. Clin Sports Med. 2015; 34 (4): 643-677. doi: 10.1016/j. Csm.2015.06.009.

4. Swords MP, Sands A, Shank JR. Late treatment of syndesmotic injuries. Foot Ankle Clin. 2017; 22 (1): 65-75. doi: 10.1016/j.fcl.2016.09.005. 